\title{
Hydrogen Isotope Exchange Properties of Porous Solids Containing Hydrogen
}

by

LEUNG HEUNG

Westinghouse Savannah River Company

Savannah River Site

Aiken, South Carolina 29808

G. C. Staack

A document prepared for 7TH INTERNATIONAL CONFERENCE ON TRITIUM SCIENCE AND at Baden-Baden,, Germany from 9/1 2/2004 - 9/1 7/2004.

DOE Contract No. DE-AC09-96SR1 8500

This paper was prepared in connection with work done under the above contract number with the U. S.

Department of Energy. BY acceptance of this paper, the pub fisher and/or recipient acknowledges the U. S.

Governments right to retain a nonexclusive, royalty-free license in and to any copyright covering this paper, along with the right to reproduce and to authorize others to reproduce all or part of the copyrighted paper. 


\title{
Hydrogen Isotope Exchange Properties of Porous Solids Containing Hydrogen
}

\author{
L. K. Heung and G. C. Staack
}

773-A, C-149, Savannah River National Laboratory,A iken, South Carolina, 29808, l'umg. h'ung(w,sw.gou

\begin{abstract}
Porous solids such as activated alumina, silica and molecular sieves generally contain significant amounts $0 /$ hydrogen atoms in the form of $\mathrm{H}_{2} \mathrm{O}$ or $\mathrm{OH}$ even at high temperature and low humidity environment. A significant amount of this hydrogen is available for reversible isotopic exchange. This exchange reaction is slow under normal conditions and does not render itself to practical applications. But if the exchange kinetics is improved this reaction has the potential to be used for tritium removal from gas streams or for hydrogen isotopic separation.
\end{abstract}

The use of catalysts to improve the exchange kinetics between hydrogen isotope in the gas phase and that in the solid phase was investigated. Granules of alumina, silica and molecular sieve were coated with platinum or palladium as the catalyst. The granules were packed in a 2-cm diameter column for isotope exchange tests, Gas streams containing different concentrations of deuterium in nitrogen or argon were fed through the protium saturated column. Isotope concentration in column effluent was monitored to generate isotope break-through curves. The curves were analyzed to produce information on the kinetics and capacity of the material. The results showed that all materials tested provided some extent of isotope exchange but some were superior both in kinetics and capacity. This paper will present the test results.

\section{INTRODUCTION}

Modem tritium processing equipment at the Savannah River Site (SRS) is enclosed inside gloveboxes to reduce tritium release to the environment. Tritium that escapes the primary containment of the equipment is con fined in the glovebox nitrogen atmosphere. This atmosphere is constantly circulated through the tritium stripping system, illustrated in Figure 1, in which the tritium is oxidized to oxide (tritiated water) and then absorbed in a dryer (molecular sieve bed). This process creates a very dry glovebox atmosphere. The difference in moisture level between the glovebox and the room causes moisture to diffuse into the glovebox atmosphere, increasing the load on the dryer (thereby decreasing the time between dryer desorbtion cycles). The amount of this "diffuse-in" moisture accounts for about $80 \%$ of the total moisture captured by the dryer. $\{$ When one dryer becomes saturated, flow is switched to a second, identical dryer and the first is desorbed.

The desorbed water containing tritium is then reduced (cracked) using hot magnesium beds and the hydrogen isotopes are separated, The separation step uses about $90 \%$ of the isotope separation capacity of the facility. If the moisture diffusion and capture can be eliminated or significantl y reduced, the requirement for water cracking and isotope separation will be greatly reduced. Furthermore, if the stripping process does not require the cracking of water, the contaminated solid waste $(\mathrm{MgO})$ can be eliminated.

One way to reduce the moisture diffusion is to operate the glovebox at a moisture level closer to room humidity to reduce or eliminate the driving force for diffusion. With the present oxidation-absorption process, this is impossible, because the dryer keeps the glovebox atmosphere dry. To permit high moisture operation, a new tritium stripping process must be developed. The key is to remove low levels of tritium from the moisture containing glovebox atmosphere without removing the moisture itself. The idea is to use a solid material containing exchangeable protium as the base material. When a gas stream containing tritium and moisture is brought into contact with this material, tritium in the gas phase (elemental or oxide) exchanges with protium in the solid

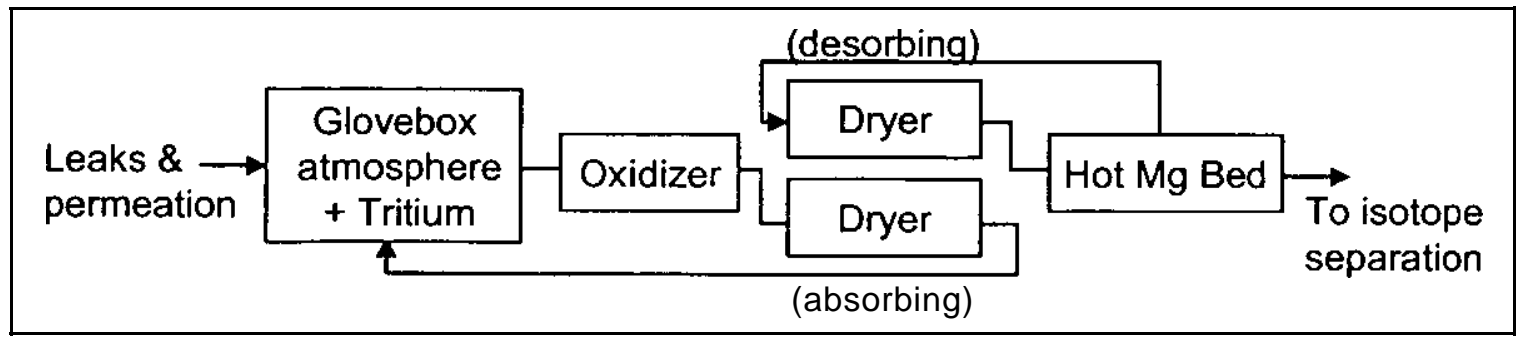

Figure 1. Schematic of Current SRS Tritium Shipper System 
phasethereby removing tritium from the gas stream with no impact on the process moisture level. When the exchange material reaches equilibrium with the tritium in the process stream, it is regenerated by reverse exchange (purging with protium). The exchanged tritium is recovered with isotope separation. The exchange concept is illustrated in Figure 2, with exchangeable hydrogen represented as h ydrox yl groups.

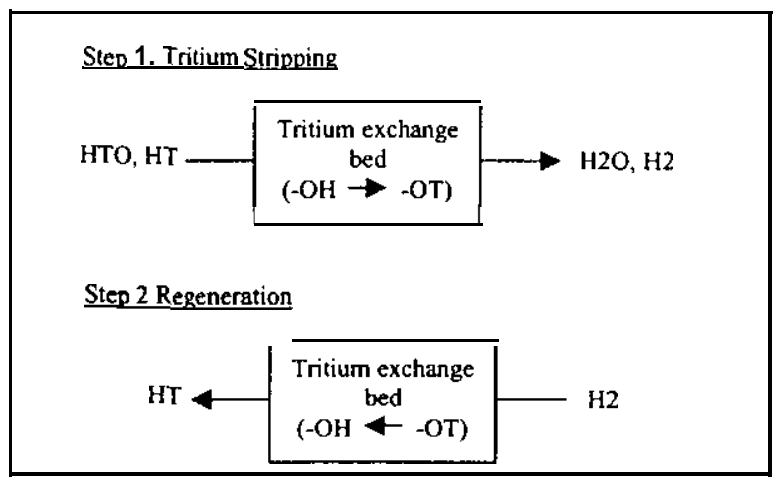

Figure 2. Isotope exchange concept to recover tritium.

\section{EXPERIMENTAL}

\section{ILA. Sample Preparation}

Four materials were examined in this investigation The first was I $\% \mathrm{Pt}$ on alumina in the form of $1 / 8$ " spheres purchased from Engelhard. The second sample tested was $1 . \mathrm{S} \% \mathrm{Pt}$ on hydrogen molecular sieve, purchased from Zeolyst International (ZeolystSD02021 Platinum Catalyst). The third sample, also from Zeolyst International, was a hydrogen zeolite without Pt (CBV 780). The fourth sample tested was a nano particle alumina coated with $2 \% \mathrm{Pt}$ from Nanophase Technologies.

In order to minimize channeling and to produce roughly similar pressure drops across the test column 1.9$\mathrm{cm}$ diameter, 16- $\mathrm{cm}$ long), each as purchased sample was modified prior to testing. The alumina spheres from Engelhard were crushed and only 10-20 mesh particles were tested. Both samples from Zeolyst International arrived as extrudate about $6-\mathrm{mm}$ long. These pieces were broken up into pieces of less than about $2 \mathrm{~mm}$. The nano particle alumina from Nanophase Technologies arrived as a tine powder. Thepowder wasmixed with water to make a paste and was dried in open air to make a cake. The dry cake was then broken up to granules between 10 and 20 mesh, soaked with a $\mathrm{PtCl}_{4}$ solution and reduced. Tbe reduction was performed by flowing hydrogen through tbe sample at 350 " $\mathrm{C}$ for 2 hours followed by 400 ${ }^{\circ} \mathrm{C}$ for 1 hour.

\section{II.B. Experimental Apparatus}

The experimental apparatus is comprised of a gas manifold, a U-shape column and an online mass spectrometer. The gas manifold consists of 'A-inch

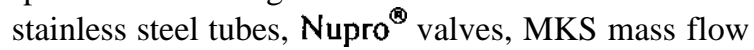
controllers and pressure transducer. The test column is $3 / 4-$ inch diameter, 6-inch long stainless steel, and has a volume of $44 \mathrm{cc}$. The mass spectrometer is a Prisms Quadrupole Model QMS 200 M 1, Mass range I-100 am., SEM/Faraday Detector and Gas Tight Ion source with Dual Tungsten Filaments, from Pfeiffer. A schematic is shown in Figure 3.

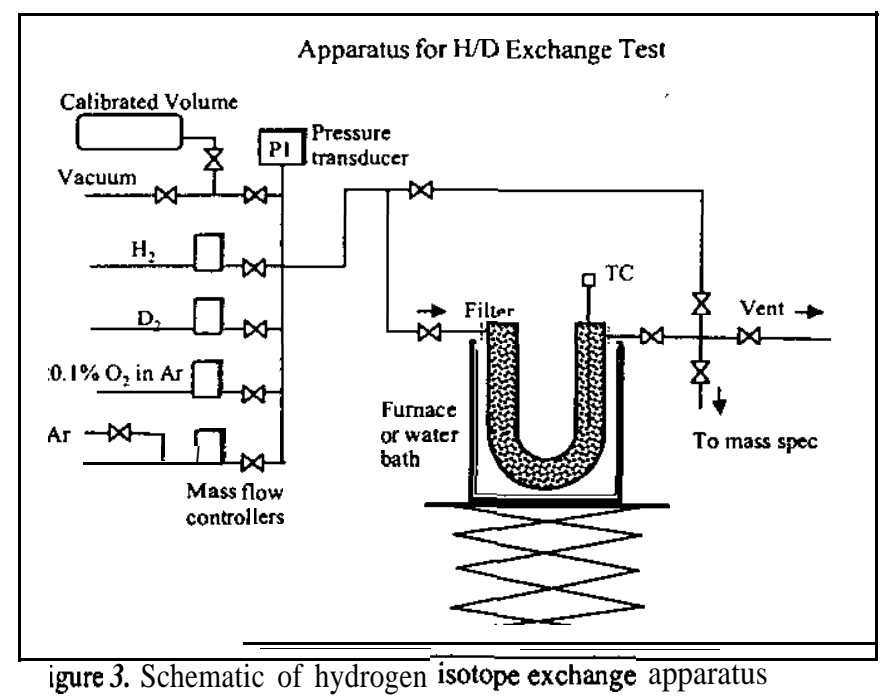

II.C. Experimental procedure

Approximately 40 cubic centimeters of sample were placed in the U-shape test column for $\mathrm{D} / \mathrm{H}$ exchange testing. The sample was handled in open air and was assumed to be in equilibrium with atmospheric moisture. The tests were conducted at room temperature, except for a few special tests at elevated temperatures. A test, in general, can be divided into three steps. The first step was to saturate the test material with protium by typically flowing 50 seem via a MKS flow controller through the column. Second, the feed gas was then switched to 50 seem deuterium. Column effluent was continuously monitored using a Pfeiffer Prisms QME spectrometer with a cycle time of IO seconds. The deuterium displaced the protium and only protium exited the column until the breakthrough of deuterium began. Low levels of $\mathrm{H}_{2} \mathrm{O}$, $\mathrm{HDO}$ and $\mathrm{D}_{2} \mathrm{O}$ were also present. As time increased, HD went through speak then decreased to near zero, Later, $\mathrm{H}_{2}$ concentration decreased to near zero while $\mathrm{D}_{2}$ increased to near 1000/.. When deuterium breakthrough was complete, the flow was switched back to protium, to 
observe the reverse exchange prope flies. The test concluded with complete protium breakthrough.

\section{II.C. Data Analysis}

From the concentration versus time data, the following can be calculated: the processing time duration, average exit gas composition and the amount of gas exchanged when 5\% and 95\% of the feed isotope breaks through the column. The 50/. and $95 \%$ are based on the total moles of protium in $\mathrm{H}_{2}, \mathrm{HD}, \mathrm{H}_{2} \mathrm{O}$ and $\mathrm{HDO}$, or the total mole of deuterium in $\mathrm{D}_{2}, \mathrm{HD}, \mathrm{D}_{2} \mathrm{O}$ and HDO. A sample performs well if it shows a long duration of processing time before $5 ? 4$ of feed breaks through, a short time difference between 5 and $95 \%$ breakthrough, and a large amount of exchanged isotope. Figure 4 demonstrates a typical $\mathrm{H}$, to $\mathrm{D}_{2}$ exchange chromatography.

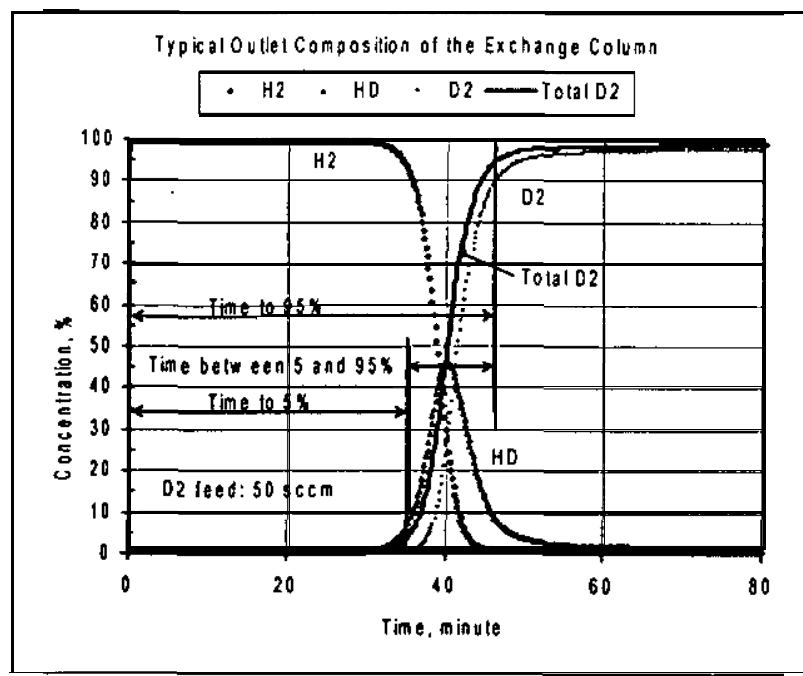

igure 4. Typical outlet composition of the exchange column and data anal ysis method.

\section{RESULTS}

\section{III.A. $1 \%$ Pt on Alumina}

The first sample tested was I\% Pt on alumina. This sample was used as a reference material because some exchange data had been previously generated. ${ }^{2} 5^{\circ} \mathrm{A}$ breakthrough was achieved thirty one minutes after the introduction of a 50 seem $\mathbf{D}_{\mathbf{2}}$ stream, corresponding to 2.3 moles of exchangeable hydrogen per kilogram of sample. $95 \%$ breakthrough occurred thirty-one minutes later, with 3.5 moles of hydrogen per kilogram of sample exchanged. During regeneration, when protium is fed into the column to exchange with deuterium, the protium broke through immediately and took 197 minutes to reach $95 \%$ breakthrough. At this point the gas exchanged was 2.5 mole/kg.

Deuterium, the heavier isotope preferentially remains in the solid phase compared with the lighter protium. This makes this type of material efficient for stripping tritium from the gas phase. During regeneration, when protium or deuterium is used to exchange out the tritium, longer residence time and/or higher temperature are possible ways to improve regeneration efficiency.

\section{III.B. 1.5\% Pt on Hydrogen Molecular Sieve}

The second sample tested was hydrogen molecular sieve (hydrogen zeolite) containing $1.5^{\circ} \% \mathrm{Pt}$. A total of 7 deuterium exchange $\left(D_{2}\right.$ exchanges $\left.H_{2}\right)$ and 6 protium exchange $\left(\mathrm{H}_{2}\right.$ exchanges $\left.D_{2}\right)$ tests were run on this sample.

The first test was run with deuterium feed at 50 seem, the same rate as the alumina tests earlier, The exchange data showed a very long period of no deuterium in the exit gas and a sharp breakthrough curve, indicating good performance. At 5\% breakthrough the elapsed time was 33.4 minutes $(2.85 \mathrm{~mol} / \mathrm{kg})$, versus 30.7 minutes $(2.26 \mathrm{~mol} / \mathrm{kg})$ for the alumina, significant improvement in exchange capacity. The time between 5\% and 95\% breakthrough is 10.5 minutes versus 30.71 minutes for the alumina. This again is a significant improvement. At 95\% breakthrough the exchanged isotope is $4.39 \mathrm{~mol} / \mathrm{kg}$, versus $3.50 / \mathrm{kg}$ for the alumina. The hydrogen molecular sieve showed much higher exchange capacity and exchange rate than the alumina.

The regenerative test was performed under the same circumstances as the alumina sample, 50 seem $\mathbf{H}_{2}$. A clear but dispersed breakthrough curve was generated, indicating that the heavier deuterium prefers the solid phase. It took only 6.5 minutes to reach $5 \%$ breakthrough, but 103 minutes to $95 \%$ breakthrough. At 95\% breakthrough the exchanged isotope was 3.52 mole/ $\mathrm{kg}$, recovering nearly all of the deuterium. This material showed significant improvement over the alumina in regeneration as well,

Subsequent tests under the same conditions demonstrated similar results with a decreasing trend in both capacity and kinetics. The small change might be due to the reduction of water content in the molecular sieve, since the feed gas was completely dry,

An additional test included the addition of $50 \mathrm{sccm}$ argon to the 50 seem deuterium feed. The change did not seem to reduce the exchange performance, indicating favorable kinetics. The time between 5\% and 95\% 
breakthrough was actually reduced from 10 to 5 minutes. More tests are needed to confirm this. A similar test was performed to test the regenerative properties. The usual flow rate of 50 seem $\mathrm{H}_{2}$ was reduced to 25 seem. The increased residence time was expected to reduce the amount of protium needed to reach the same regeneration. Time to $5 \%$ breakthrough was 9.9 minutes compared with 6.5 minutes where $50 \mathrm{sccm}$ was the feed rate. The time to $95 \%$ breakthrough was 175 minutes compared with 96.6 minutes. Both increases are less than 2 fold, indicating reduced rate requires less gas to regenerate.

Another test used a low concentration of deuterium in argon with a small amount of oxygen. The feed consisted of 1,48 and I seem of deuterium, argon and oxygen, respectively. The run continued for 185 minutes. There was no breakthrough of deuterium for the duration of the run. If the exchange capacity remained at $3 \mathrm{~mol} / \mathrm{kg}$, at, I seem, it would take 21.2 hours to breakthrough. This run was not long enough to show the breakthrough, but it did show the presence of oxygen did not adversely affect the isotope exchange for at least the first 3 hours.

An additional test was performed to determine whether a higher temperature of 60 " $\mathrm{C}$ would improve regeneration performance. It produced a sharper breakthrough curve and shortened the time between $5 \%$ and $95 \%$ breakthrough by 33 minutes, from 96.6 to 63.9 minutes. But some of this reduction might be attributed to the reduced exchange capacity, as indicated by subsequent tests.

To test whether the decrease in sample capacity was due to moisture losses, the sample was removed from the column and exposed to open air for over a week to equalize with room moisture. The sample was then placed back in the column for testing. For the deuterium test the $5 \%$ breakthrough time was 142 minutes! This is more than 4 times the first run of this sample and close to 5 times the alumina after it went through similar exposure to ambient moisture. The exchange capacity at $95 \%$ breakthrough was $14 \mathrm{~mol} / \mathrm{kg}$. This is equivalent to 25 weight percent of water in the solid material. This capacity can be preserved if the feed stream contains moisture in the 40 or $50 \%$ relative humidity level.

\section{III.C. Hydrogen Molecular Sieve without Pt}

To illustrate the importance of platinum as a catalyst, a hydrogen molecular sieve without $\mathrm{Pt}$ on it was also tested. 57. breakthrough occurred immediately on both the initial and regenerative exchanges. $95 \%$ breakthrough took 39.1 and 2.8 minutes, corresponding to 0.29 and 0.06 moles of hydrogen exchanged respectively.

\section{III.D. 2\% Pt on Nano Particle Alumina}

The final series of tests were on nano panicle alumina with $2 \% \mathrm{Pt}$. The initial exchange run with 50 seem exchange gas gave $50 /$. and $95 \% \mathrm{D}_{2}$ breakthroughs at24.0and 31.2 minutes. These times correspond to 1,27 and 1.41 moles of hydrogen exchanged. The regenerative run gave $5 \%$ and $95 \% \mathrm{H}_{2}$ breakthroughs at 4.2 and 65.4 minutes. These times correspond to 0.2 I and 1.04 moles of h ydrogen exchanged.

Another test performed on the nano alumina included a small amount of oxygen in argon in the feed gas such that if all the added oxygen were converted to water, it would comprise $1 \%$ of the feed. The thought was to help maintain or increase the water content in the solid, and therefore maintain or increase the exchange capacity. The results are almost exact duplicates of the initial tests, except that the deuterium exchange capacity actually decreased from 1.4 to $1.1 \mathrm{~mol} / \mathrm{g}$. The amount of added oxygen might have been too small to show any effect. More tests would be needed to study this effect.

An additional test was run with a 50/50 mixture of protium and deuterium containing small amounts of oxygen and argon. The rates are 24,24,0.26 and 1,03 seem, respective y. Deuterium was effective y removed from the feed mixture for 26 minutes when $5 \%$ of it broke through. The exchange capacity at $95 \%$ breakthrough was $0.78 \mathrm{~mol} / \mathrm{kg}$, or $80 \%$ of the exchange capacity when pure deuterium was used in the feed.

The final test on this sample was a low-flow rate (2o seem) regeneration test with small amounts of oxygen and argon in the feed (O. 13 and $0.52 \mathrm{sccm})$. The shape of the exchange curve is similar to the previous regenerative test at 50 seem with argon and oxygen. The exchange capacity and the amount of protium needed for exchange are tbe same. Contrary to the results from the similar test performed on tbe hydrogen molecular sieve, the slower flow rate (bigher residence time) did not improve the performance.

\section{CONCLUSIONS}

Among tbe 3 types of materials tested for isotope exchange application, b ydrogen molecular sieve with $1.5 \%$ Pt catalyst was found to be the best. It demonstrated the best kinetics and bad a capacity of up to 14 moles per kilogram of material. This was 4 times the capacity of activated alumina, and 10 times of that of nano alumina. Other zeolites such as type 4A and 5A will be tested to see if they have similar isotope exchange properties. 
Besides favorable capacity and kinetics. as shown bv the ratio of the time between $5 \%$ and $95 \%$ breakthrough to the time of $95 \%$ breakthrough, Pt coated hydrogen molecular sieve also displayed a large isotopic effect. The heavier isotope prefers the solid phase to the gas phase. This property can be applied in isotopic separation and should be further investigated.

The tests conducted in this work were screening in nature and the conclusions are preliminary. Exchange performances under various feed conditions and temperatures will be further investigated. Other variables that will need future detailed studied include response to moisture level and cycle number. Tbe effect of a nitrogen atmosphere needs to be evaluated due to the potential complication of ammonia formation.

\section{ACKNOWLEDGMENTS}

Guidance and assistance from Laura Tovo, William Spencer and William Boyce of SRNL Anal ytical Development Section in tbe selection and startup of the mass spectrometer are highly appreciated.

\section{REFERENCES}

(1) L. K. Heungand M. L. Rhode., Fmion Science and Technology, vol. 41, May 2002, p583.

(2) L. K. Heung, G. W. Gibson and M. S. Ortman, Fusion Technology, vol. 21, March 1992, p588. 